\title{
Between horrid and science. Girolamo Segato's strange anatomy (1792-1836)
}

\author{
Lippi, D. and Weber, D.* \\ Department Experimental and Clinical Medicine, Università degli Studi di Firenze - UNIFI, \\ P.zza S.Marco, 4 - 50121, Firenze, Itália \\ *E-mail: domizia.weber@unifi.it
}

\begin{abstract}
Fascinating methods and materials for preserving dead bodies from decomposition were used by different populations in any time for various reasons. During the XVIII-XIX centuries, the necessity of preserving bodies increased, in order to improve anatomical studies, and many methods were developed. Girolamo Segato (1792-1836) devoted himself to the art of "petrifaction", discovering a particular procedure, which permitted him to obtain amazing results. His sudden death prevented him from revealing his method: recent studies have disclosed unexpected contacts between Segato and American scientists, who were very interested in his work.
\end{abstract}

Keywords: petrifaction, Segato, anatomical studies.

\section{Introduction}

Humans around the world and throughout history have developed fascinating methods and materials for preserving dead bodies from decomposition: the reasons for this practice are various and distinct for each culture. The ancient Egyptians used mummification because the preservation of the body was an essential requirement for the afterlife; during the crusades, soldiers killed in battle needed to find a new way home, as Pope Boniface VIII in 1300 had prohibited to cut corpses into pieces for transport or burial. In more recent times, the practice became a matter of necessity: anatomy students needed a preservative that would allow a more careful and lengthy examination of a body without the worry of decomposition. Moreover, embalming methods became critical for transportation or viewing associated with funeral and memorial celebrations, to display the body as it is, it's the tradition in many cultures and faiths. Restorative art emerged as an important sub-discipline in the early 1900s and nowadays institutions of mortuary science provide detailed instructions, and special schools devoted to cosmetic preparation are very common. In this long-lasting research, many techniques have been tested and some of them are enveloped in mystery.

This is the case of Girolamo Segato's (1792-1836) method, which is surrounded by a thick halo of obscurity.

\section{A Forerunner of Indiana Jones?}

Segato was an Italian naturalist and cartographer: he was born in Sospirolo, close to Belluno in Northern Italy. As a child, he learned basic sciences from the priest of Sospirolo, developing a deep interest in natural sciences (LIPPI and ORLANDINI, 2002).

From 1818 onwards, Segato participated to several archaeological expeditions to Egypt, where he learnt the techniques of mummification (GARRISON,1925, 1927).

After many misadventures, in 1824 he moved to Florence where he got in touch with the intellectual milieu, thanks to his fame as a pioneer. He had the opportunity to introduce himself to the Gran Duke of Tuscany Leopoldo II, who showed great interest for his investigations, promising him an economic support which, in reality, he never received.

Among many economic difficulties, Segato continued his experiments - amalgam of metals, artificial amber, composition of colours - studying different methods to preserve organic substance and to indurate animal bodies. Despite his excellent results, he was sidelined by the society of his time and hampered by the Church.

For this reason, he decided to destroy all his notes.

In this period, among other specimens, he crafted a handsome table, inset with what looked like polished stones but were, in fact, human organs, preserved, cut into geometric shapes, and fitted into a colorful mosaic.

With the passing of time, his popularity increased: the Accademia della Val Tiberina Toscana (1835) named him correspondent fellow and the Società medico-chirurgica di Bologna declared to be interested to examine his preparations.

The curiosity towards his method improved, but there was no consensus on his work.

Beset by debts, censured by academics, looked on by clergy, Segato took to the grave the secret of his technique, which, despite numerous studies and attempts to imitate, remains mysterious: he died in 1836 at only 44 years, and was buried in the Cloister of the Basilica of Santa Croce. This is the epitaph on his tomb: "Here lies decayed Girolamo Segato from Belluno, who could have been totally petrified if his art had not died with him”.

\section{The Cabinet of Curiosities}

After his death most of the collected material disappeared due to the pillages of his family house both in 1848 during the war with Austria and during the First World War.

Today, many of Segato's surviving petrifactions are exhibited in the Museum of the Department of Anatomy in 
Florence (http://www.unifi.it/unifi/anatistol/anatomia/ segato/index.htm).

Some pieces, such as a young female breast and a female scalp, belong to the original nucleus of the 19th century Physiological Museum; others have different origins. Some of them come from the Civic Museum of Belluno, part derive from Segato's heirs and part from the Institute and Museum of History of Science in Florence. The latter collection results particularly interesting because, besides the famous inlaid table, human anatomical preparations and other zoological specimens, it shows the evolution of his work, represented by several proofs of the most famous final products (breast, scalp, inlays). Some of these specimens were exhibited in a ground floor hall of the Museum building which was invaded by the muddy Arno water during the flood of 1966 and now they are greatly damaged.

\section{Brain Drain}

Between the Thirties and the Forties of the XIX century, many American literates and doctors travelled in Europe: among them, Richard Henry Wilde and Valentine Mott.

Both of them visited Florence and got in touch with Girolamo Segato.

Valentine Mott (1785-1865), one of the most influential American surgical leaders of his time, is recognized as a pioneer vascular surgeon, and consequently the Father of American Vascular Surgery. He spent seven years in Europe and he published his experiences in his book, Travels in Europe and the East (MOTT, 1842).

Mott's (1842, p. 108-110) account of his acquaintance with Segato is reported:

The most novel and piquant treat of all others to me in the beautiful capital of Florence, was my several visits to Signor Sigato, a scientific gentleman to whom I was introduced by my excellent friend and fellow countryman, James Thompson, of New-York, who has been residing with his family many years in Florence.

Signor Sigato possessed a wonderful art, unique, and unknown to all the world besides. Incredible, if not marvellous, as it may seem, he had discovered a chemical process by which he could actually petrify, in a very short time, every animal substance, preserving permanently, and with minute accuracy, its form and internal texture, and in a state of such stony hardness that it could be sawed into slabs and elegantly polished!

He had in this way formed a museum of various animals, such as frogs, fishes, toads, snakes, and a great variety of parts of the human body in a natural and diseased state. In my presence he threw the human liver, lungs, heart, and other parts thus petrified, about the floor with perfect impunity, and without the least injury being done to them. Still more curious, he had, with Italian taste, cut them into small polished squares, and arranged them in complete tables of mosaic work! so that it gave him as much delight as it did me astonishment, to find that I could with my finger designate to him, on this precious centretable for a surgeon's drawing-room, the appropriate name and character of each individual object thus spread out before me in a pathological chart of real specimens. Thus a pulmonary tubercle or ulcer here, a hydatid of the liver there, a cicatrix in the brain in another compartment, and a calculus in the kidney or ossification of the heart's auricles and valves in a fourth.

This extraordinary man must have inherited the magic shield of Perseus, that, with the snaky tresses of the Gorgon Medusa's head, enabled him to convert everything he touched into stone.

Mott (1842, p. 108) appreciated Segato's discovery and twigged its possible development from a scientific point of view: he realized the difficult economic situation of Segato and invited him to the USA:

It struck me immediately that, for all anatomical and surgical purposes, and all objects of natural history, this was an art of inappreciable value, and the most desirable ever discovered; and with that view I conversed with him relative to a visit to our country, believing it would be of national importance if we could have the benefit of his services. I even entered into some preliminaries of a negotiation with the design of obtaining him for my own purposes, but I found him sadly involved in debt, and that his demands were too exorbitant to be complied with.

His offer however could not be accepted:

I, however, made him liberal offers, and did not entirely despair that he would have acceded to them, when, to my regret, about three weeks after leaving Florence, I was informed by letter that he was suddenly attacked with a violent inflammation of the lungs, which proved fatal; and, what is as much to be deplored, that his unprecedented discovery perished with him. (MOTT, 1842, p. xx)

Mott (1842, p. 108) is aware of the fact that Segato's method is unknown:

He never would divulge the least part of his marvellous process; but, when pressed by me on the subject, hinted that he had acquired it in his various journeys in remote Eastern countries; and it is fondly to be hoped that some one may ere long appear who, in pursuing this inquiry, will be enabled to recover the art among those people from whom he intimated that he had obtained it.

It is worthy of observation how, in the extraordinary process we have described, art accomplishes in so brief a time what nature requires so long a period to effect, and then never with anything comparable to the perfection, we may say almost identity, with which this mode preserves an exact facsimile of the original; in truth, the original itself.

In all the natural petrifying processes, only the external configuration and character generally, and not even the colour is retained, and rarely the texture, except in the case of ligneous substances, where both the fibres and colours are tolerably well sustained.

But in this surprising and almost magic art, not only, as we have said, the precise exterior outline is faithfully and exactly represented, but also the most minute and delicate interior arrangement of structure admirably perpetuated; as, for example, the entire viscera of the chest and abdomen, with all their varied and beautiful convolutions, were clearly exhibited, retaining even the colours of the blood vessels, in preparations of frogs, birds, and other animals, besides the human body. 
In the same period, at the beginning of 1836, Richard Henry Wilde (1789-1847) also visited Florence: besides being an attorney who was frequently engaged before the Supreme Court of the United States, an attorney-general of Georgia, and a U.S. Congressman for several years, Richard Henry Wilde was famous for being a poet and a historian.

In Florence, he very probably visited Segato's laboratory and met the lawyer Giuseppe Pellegrini, who was a keen friend of Segato's and one of his most passionate apologists.

Richard Wilde received from Pellegrini a short draft about Segato's discovery and on January 10th 1836 he sent it to his friend in Augusta, Dr. A. Cunningham, who offered it for publication in the Southern Medical and Surgical Journal.

Dr. Milton Antony (1789-1839), the founder of the Medical College of Georgia, was the editor and in July the paper was published (WILDE, 1936).

Wilde used Pellegrini's account to write this article in the first person, but the tone of the information reveals a deep knowledge of the matter: Giuseppe Pellegrini had already written a defence of Segato's method against his detractors and he jumped at the opportunity to help his friend, spreading his fame across the ocean, hoping in a stroke of luck (PELLEGRINI, 1835).

Wilde $(1936$, p. 83; 93; 94) took this account on board, adding his personal view and quoting also Mott's visit to Segato's cabinet:

So perfectly natural is the colour and appearance of the specimens of morbid anatomy thus preserved, that a most distinguished surgeon of our country, Dr. Mott, of New York, who recently visited Segato's cabinet, on being shown this tablet, named immediately various parts of the body, and the particular disease with which they had been affected.

Wilde (1936, p. 83; 93; 94) signed his paper from Florence January 10th, but it was published in July: the editor was forced to add a short note:

It is now our painful duty to announce ...the death of Signor Girolamo Segato [sic]. This is an event greatly to be deplored. There was a lively hope that Mr. Wilde would be enabled to induce him to come to the United States, where his genius, scientific attainments, and untiring perseverance might have spread an influence around, the value of which to this country no one could estimate. With regard to the process by which he effected these wonderful preservations above described, it is greatly to be feared the world will never be informed; for, at the date of the last communication from Mr. Wilde, no account of it had been found.

Wilde's article was picked out by many other journals, which seized the opportunity to deal with such an odd matter, which is still surrounded by mystery (New England farmer, and gardener's Journal, 1837)

\section{Dust Thou Art, and Dust Thou Wilt Again Be}

Despite the attempts which were made to discover his secret by examining the objects, Segato's method remains unveiled.
As a matter of fact, he very probably used multiple and different procedures.

The specimens preserved in the Florentine Anatomical museum can be divided in three different groups according to the conservation's method (Florence, 1850):

1 dry anatomical specimens with vascular injection. Even if they show an uncommon technical skill and a perfect knowledge of Anatomy, they don't differ from similar preparations present in any anatomical collection of the last centuries.

2 parchment preparations: Segato probably used chalk to fill intestines and to shape moulds upon which he laid strips of skin (SPIRITO, 1939).

3 "petrified" pieces (inlaid table, whole animals, sliced organ-containing reliquary). It has to be emphasized that several "scientists" in the period bridging the 18th and the 19th centuries tried to use mummification or petrifaction methods. Many of their techniques are known and were based on the use of Arsenic, Silicon, Alum, Calcium salts, and other substances; nevertheless the results were not comparable to those of Segato. On the other hand, even if chemical investigations on Segato's specimens could offer important findings, and if preliminary studies seem to exclude the presence of Silicon, the mere detection of chemical elements cannot surely clarify the complicated procedures performed by "the man who could transform organic matter into stone" and therefore Segato's method has been, is and will probably remain a mystery.

\section{References}

Florence. Editorial correspondence. Boston Medical Surgery Journal, 1850, vol. 43, p. 262-268.http://dx.doi.org/10.1056/ NEJM185010300431307

GARRISON, FH. A note on Girolamo Segato. Bulletin of the New York Academy of Medicine, 1927, vol. 3, p. 7-481. PMid:19311560 PMCid:PMC2393576.

GARRISON, FH. Valentine Mott. Bulletin of the New York Academy of Medicine, 1925, vol. 6, p. 209-214.

LIPPI, D. and ORLANDINI, G. New considerations about the preservation method used by Girolamo Segato (17921836). In: Anais LVI Congresso Società Italiana di Anatomia, Pisa, 2002. 178 p.

MOTT, V. Travels in Europe and the East. Harper \& Brothers, 1842. p. 108-110.

New England farmer, and gardener's Journal, Boston, 1837.

PELLEGRINI, G. Dell'artificiale riduzione a solidità lapidea, e inalterabilità degli animali, scoperta da Girolamo Segato. Firenze: V. Battelli e Figli, 1835.

SPIRITO, F. A proposito di un metodo personale di pietrificazione dei pezzi anatomici. "Athena"-Rassegna mensile di Biologia, Clinica e Terapia, Tip. L. Proja, 1939.

WILDE, RH. Signor Segato's Discovery. Southern Medical and Surgical Journal, 1936, vol. 5, n. 2, p. 83-97.

Received July 9, 2013 Accepted March 13, 2014 